The Journal of The Brazilian Crustacean Society

e-ISSN 2358-2936 www.scielo.br/nau www.crustacea.org.br

\title{
Mating and ejaculate allocation pattern in the kelp crab Taliepus dentatus (Decapoda: Epialtidae)
}

\author{
Katrin Pretterebner 1,2,3 (D) orcid.org/0000-0003-1150-7475
}

Javiera Sanhueza ${ }^{2}$ (D) orcid.org/0000-0002-4948-7783

Jorge López ${ }^{2,4}$ (D) orcid.org/0000-0003-4075-5873

Luis Miguel Pardo 2,3 (D) orcid.org/0000-0002-8179-5057

1 Universidad Austral de Chile, Facultad de Ciencias, Programa de Doctorado en Biología Marina. Valdivia, 5090000, Chile.

KP E-mail: k.pretterebner@hotmail.com

2 Universidad Austral de Chile, Instituto de Ciencias Marinas y Limnológicas, Facultad de Ciencias, Laboratorio Costero de Calfuco. Valdivia, 5090000, Chile.

JS E-mail: javiera.sanhueza@alumnos.uach.cl

JLE-mail: jorgelopezbascur@gmail.com

LMP E-mail: luispardo@uach.cl

3 Centro de Investigación de Dinámica de Ecosistemas Marinos de Altas Latitudes (IDEAL). Valdivia, 5090000, Chile.

4 Universidad Austral de Chile, Escuela de Graduados, Programa de Doctorado en Ciencias de la Acuicultura. Av. Los Pinos s/n Balneario Pelluco. Puerto Montt, Chile.

ZOOBANK: http://zoobank.org/urn:lsid:zoobank.org:pub:613E7FBE-8389-4CDDAAE1-ECBD1AC30D78

\section{Abstract}

Ejaculate allocation patterns vary widely among species and often depend on characteristics of the individual. However, it is poorly known whether ejaculate allocation patterns change in response to distinct ontogenetic stages (i.e., adolescent $v s$. adult). The present study aims to describe the mating process and test variations in ejaculate allocation in response to the ontogenetic stage of the Chilean kelp crab Taliepus dentatus (H. Milne Edwards, 1834). Mating consists of the following sequence: (1) pre-copulatory guarding (i.e., male grasping female and/or caging female between legs), (2) copulation in sternum-to-sternum position, and (3) post-copulatory guarding (i.e., male grasping female or carrying her around by the chelae). The mating behavior and ejaculate allocation pattern differed between the two contrasting male ontogenetic stages. Adolescent males generally delivered less ejaculate in repeated short copulations and adult males transferred more ejaculate in a single extended copulation. Ejaculate allocation in adolescents was dependent on female size, but not so in adults. Variation in the ejaculate allocation pattern may be common in species with contrasting male ontogenetic stages, where less competitive males (i.e., adolescents) economize their limited seminal reserves. Conversely, adults which have a greater capacity to produce seminal material (fluids + spermatozoa) may invest greater quantities of seminal material.

\section{KeYwords}

Behavior, morphometric maturity, ontogenetic stage, reproduction, vasa deferentia 


\section{INTRODUCTION}

Ejaculate allocation strategies and prudent ejaculate expenditure aim to maximize the reproductive output and are present in males of many taxa of terrestrial insects, birds, and fishes (Wedell et al., 2002) as a response to energetically costly production of seminal materials, especially seminal fluids (Dewsbury, 1982). Ejaculate allocation refers to the ability of males to adjust the amount of ejaculate transferred to females. In crustaceans, the pattern of allocation of spermatozoa varies widely among species and depends on characteristics of the individual as well as the socio-sexual context. In a non-competitive scenario, important determinants of the spermatozoal quantity transferred to females are size of the female (Gosselin et al., 2003; Brockerhoff and McLay, 2005; Rubolini et al., 2006), size of the male (Gosselin et al., 2003; Hines et al., 2003; Sato et al., 2006) and mating history (Kendall et al., 2002; Van Son and Thiel, 2006). Males may modify the amount of spermatozoa delivered to females in response to the socio-sexual context, notably by adjusting ejaculate size to match the risk of sperm competition (Wedell et al., 2002). The probability of sperm competition can be reflected in the operational sex ratio and the presence of rival males. In spider crabs (Majoidea) in particular, male ejaculate allocation patterns have been poorly studied, except for Chionoecetes opilio (O. Fabricius, 1788) (Sainte-Marie and Lovrich, 1994; Rondeau and Sainte-Marie, 2001; Sainte-Marie et al., 2002).

Majoids are generally characterized by determinate growth and cease molting after their puberty molt, which is referred to as the terminal molt (Hartnoll, 1963; 1984; 2001; McLay and López Greco, 2011; McLay, 2015). At the terminal molt the transition from adolescence to final sexual maturity (i.e., adult stage) occurs, corresponding to morphometric maturity, which is associated with acquiring full development of secondary sexual traits, such as the relative enlargement of the propodus of the chelae in relation to the carapace size in males (Conan and Comeau, 1986; Sainte-Marie et al., 1995; Mura et al., 2005). However, in males of several majoid species the onset of spermatogenesis (i.e., physiological sexual maturity) can occur before the terminal molt (Conan and Comeau, 1986; Mura et al., 2005; Corgos and Freire, 2006; Varisco and Vinuesa, 2011), thus enabling both adolescent and adult males to mate (SainteMarie et al., 1997; Sal Moyano and Gavio, 2012). In majoids, distinct patterns of mating depending on the ontogenetic stage of males have been described, such as in Libinia emarginata Leach, 1815 (Laufer and Ahl, 1995), Libinia spinosa Guérin, 1832 (Sal Moyano and Gavio, 2012) and C. opilio (see SainteMarie et al., 1997). In particular, C. opilio exhibits contrasting mating behaviors which are displayed in the two male ontogenetic stages: abbreviated precopulatory guarding, several brief copulations and optional post-copulatory guarding in adolescent males vs. pronounced pre- and post-copulatory guarding behavior and one long copulation in adult males (Sainte-Marie et al., 1997). In L. spinosa the two morphotypes differ in the duration of both pre- and post-copulatory guarding (Sal Moyano and Gavio, 2012). Studies describing the distinct ontogenetic stages in spider crabs so far have been mainly focused on differences in mating behavior, such as duration and frequency of copulation and duration of preand post-copulatory guarding (Sainte-Marie et al., 1997; Sal Moyano and Gavio, 2012), although the amount of ejaculate delivered by male C. opilio was examined (Sainte-Marie and Lovrich, 1994). Duration of copulation is often related to the amount of seminal material transferred (e.g., Sainte-Marie et al., 1997). However, information on whether distinct male ontogenetic stages can also be reflected in the ejaculate allocation pattern in spider crabs, is scarce.

The kelp crab Taliepus dentatus (H. Milne Edwards, 1834), commonly called "Jaiba Panchote", is distributed between Callao in Peru $\left(12^{\circ} \mathrm{S}\right)$ and Puerto Bueno in the Chilean Patagonia $\left(51^{\circ} \mathrm{S}\right)$, including the islands of San Félix and Juan Fernández (Fagetti and Campodonico, 1971). Its exploitation is concentrated in the austral regions of Chile, with a five-year mean annual landing of around 23.4 tons (Servicio Nacional de Pesca y Acuicultura, 2015-2019). This is an artisanal fishery with a male-only harvest regulation and oviposition in T. dentatus has been observed yearround (Fagetti and Campodonico, 1971; Retamal et al., 2009). Previous studies on T. dentatus have been mainly focused on thermal tolerance of larvae (Storch et al., 2009; 2011; Carreja et al., 2016), maternal 
investment of females (Baldanzi et al., 2018) and male seminal recovery (Pretterebner and Pardo, 2020). Knowledge about male reproductive biology is scarce despite them being the target of a fishery.

This study aims to describe the mating process in T. dentatus and understand the influence of the individual ontogenetic stage (i.e., adolescent and adult males) on the quantity of seminal material transferred from the male to the female during copulation (i.e., ejaculate).

\section{Materials and Methods}

\section{Seasonal pattern of male reproductive investment}

The vasosomatic index (VSI) represents the capacity of males to transfer seminal material with respect to their size (Sainte-Marie, 2007; Pardo et al., 2015) and fluctuation of the VSI can be interpreted as the condition of males during the reproductive cycle, indicating periods of mating and seminal reserve recovery (Pardo et al., 2019). Therefore, the VSI was estimated for male crabs of similar size (larger than $96.4 \mathrm{~mm}$ carapace length (CL)) collected from Los Molinos Bay in southern Chile (3951'16.7”'S 73²3'40.3”W) from January 2016 to May 2017 during the four austral seasons $(n=7$ in winter and spring each, $\mathrm{n}=5$ in summer and $\mathrm{n}=6$ in autumn). At the Laboratorio Costero de Recursos Acuáticos de Calfuco, Universidad Austral de Chile, individuals were sacrificed (anesthetized by thermal shock: $-20^{\circ} \mathrm{C}$ for $20 \mathrm{~min}$ ), paired vasa deferentia were dissected out (Fig. 1A) and their dry weight was determined. The VSI (expressed as a percentage) was calculated as VSI $=(\mathrm{VDW} / \mathrm{BDW}) \times 100$, with VDW being the dry weight of the two vasa deferentia (oven dried for 4 days at $70{ }^{\circ} \mathrm{C}$ and weighed to a precision of $0.0001 \mathrm{~g}$ ) and BDW being the dry weight of the crab body (oven dried for 4 days at $70^{\circ} \mathrm{C}$ and weighed to a precision of $0.01 \mathrm{~g}$ ). For the estimation of the VSI, dry weight of the crab body without legs and chelae was used to increase accuracy (Sainte-Marie, 2007; Pardo et al., 2015).

\section{Determination of adolescent and adult males}

Morphometric size at sexual maturity of males was estimated to determine the ontogenetic stage of crabs. Carapace length (CL; rostrum to mid-posterior carapace) and height of both chelae (measured across the widest portion of the propodus perpendicular to the long axis) were measured on 62 males from the same sampling location (Los Molinos Bay) using a vernier caliper. Male crabs were categorized according to their ontogenetic stage (i.e., adolescent and adult males) using the same terminology as used in Sainte-Marie et al. (2008). Adolescent males were characterized by bearing small chelae relative to their $\mathrm{CL}$, in comparison with adult males that possessed enlarged chelae.

\section{Laboratory condition and experimental crabs}

Experimental matings were conducted in the laboratory to describe the mating behavior of $T$. dentatus and to examine whether males have an ejaculate allocation pattern in response to their ontogenetic stage. Males (CL range: $87.3-119.8$ $\mathrm{mm}$ ) and females (CL range: $70.2-89.5 \mathrm{~mm}$ ) of $T$. dentatus were collected from Los Molinos Bay and transported to the laboratory where crabs were maintained separately by sex in 5001 tanks with flowing seawater, air supply $\left(\mathrm{O}_{2}\right.$ saturation was guaranteed through bubbling of water) and ad libitum food for at least 14 days to allow recovery of seminal material for mating (Pretterebner and Pardo, 2020). Experimental matings were conducted in all months from April 2017 to February 2018, except for May 2017. For experimental manipulative matings the right gonopod of males was ablated (unilateral ablation) by removing the appendage at its base with dissecting scissors to be able to estimate ejaculate transferred during one mating (Jivoff, 2003; Pardo et al., 2013; 2015 ; 2018). An experimental mating trial consisted of pairing one unilaterally ablated male with one female in an individual 1001 tank with flowing seawater. The bottom of the tank was covered with pebbles. All females used in experimental matings were in post-puberty intermolt stage (i.e., "hard-shelled" and pleon detached from carapace). Only crabs with both chelae were used in experiments. We measured CL on all individuals so that the difference between female and male CL was always constant (male CL on average 1.2 times larger than that of female) to avoid effects of great size differences in experimental pairs. 


\section{Mating behavior}

Experimental matings were recorded in highdefinition mode by video cameras equipped with infrared light to subsequently describe the mating behavior of 12 randomly selected pairs of which males in 6 pairs were adolescent and 6 pairs adult. Four behavioral variables were analyzed: (1) total duration of pre-copulatory guarding, (2) total duration of copulation, (3) total duration of post-copulatory guarding, and (4) number of copulations during the experimental period. The time spent by a mating pair in a sternum-to-sternum position was equated to copulation duration because we could not determine when the male gonopod was actually inserted or removed from the female vagina. Additionally, during copulation the opened pleon of the female was often visible below the male's carapace (Fig. 1B). End of copulation was identified by the separation of the pair or the change into a rostrum-to-rostrum, post-copulatory guarding position. If a pair mated repeatedly (i.e., more than one copulation), the total duration of each behavioral variable was calculated as the sum of the multiple durations of each behavior observed during the experimental mating trial. Each mating trial ended at the separation of the pair after mating or post-copulatory guarding, or after approximately $24 \mathrm{~h}$.

\section{Ejaculate allocation}

To determine if ontogenetic stage can explain ejaculate allocation, experimental matings were conducted in 24 pairs of which males in 9 and 15 pairs were adolescent and adult, respectively. The male and female used as a mating pair were randomly chosen from tanks where they were maintained separated by sex before the experiment. The terminal molt does not always occur at the same number of molts in the female, as in C. opilio (see Sainte-Marie et al., 2008), therefore, there is variation in the size of females which are able to copulate. After mating, the female and male were sacrificed. Both seminal receptacles and ovaries of females and the left vas deferens of males were dissected out (Fig. 1A). The dry weight of seminal receptacles, ovaries and left vas deferens was measured. Due to ablation of the right gonopod, ejaculate delivery was unilateral and the amount of ejaculate delivered to females was estimated as the difference in dry weight between the right receptacle (presumably refreshed by mating) and the left receptacle (not refreshed) (Pardo et al., 2013). We used the dry weight of the left receptacle as an approximation of its load before mating. The right vas deferens after mating was not used for further analysis because some seminal material might have escaped out of the right gonopod during mating despite its initial

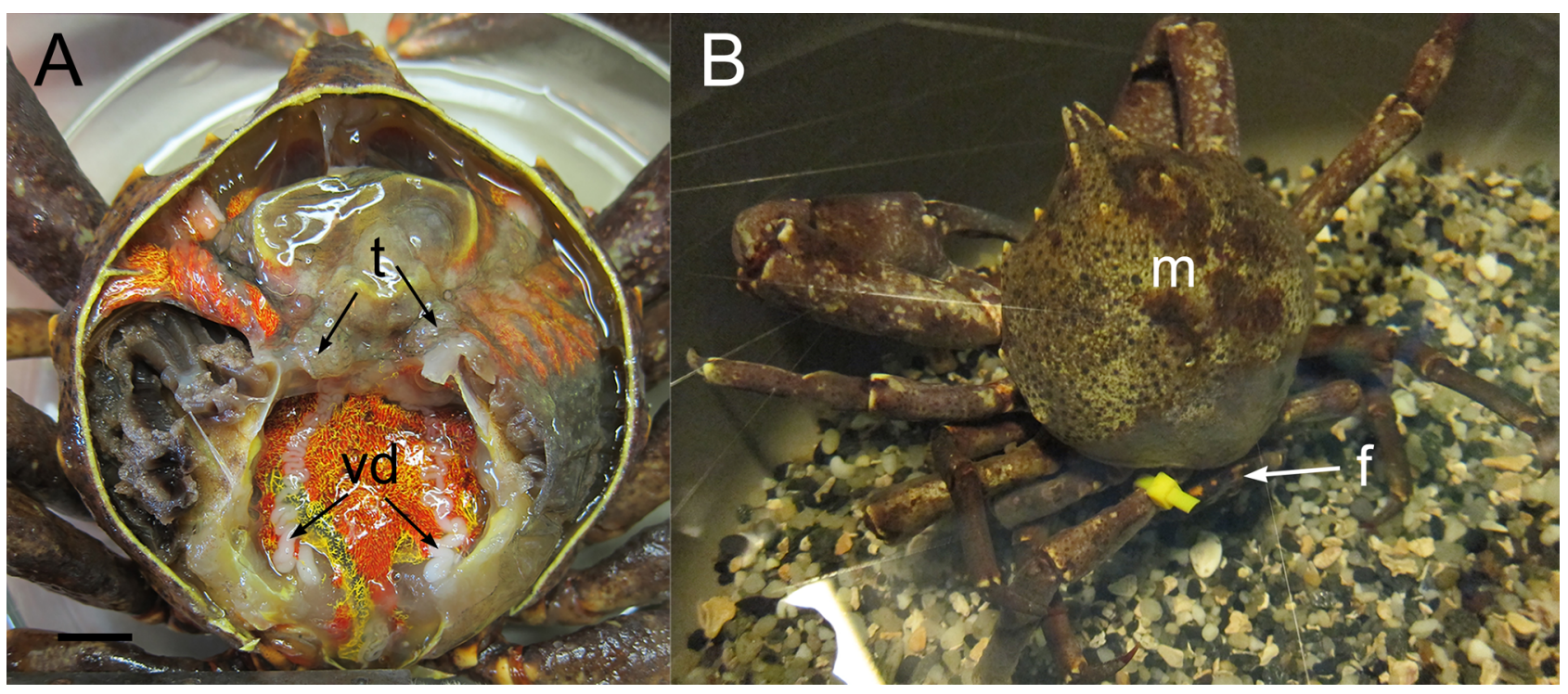

Figure 1. Procedures involved in experimental mating in Taliepus dentatus. (A) Dorsal view of opened cephalothorax displaying the male reproductive system. Dissection of paired vasa deferentia after experimental mating. Paired vasa deferentia (vd) and testes $(\mathrm{t})$ are indicated by arrows. Scale bar $=10 \mathrm{~mm}$. (B) During copulation the male $(\mathrm{m})$ was positioned above the female (f) in the sternum-to-sternum position. The opened pleon of the female was visible below the male crab, which is indicated by the arrow (photos: K. Pretterebner, photoshop). 
ablation. Instead, the seminal material present at the beginning of the trial of each male was calculated by adding twice the left vas deferens dry weight after mating to the doubled ejaculate dry weight received by the female of the mating pair. The reproductive status of females was recorded (i.e., non-ovigerous or ovigerous; the embryo stage was not determined). Females were visually examined for the presence of a post-mating sperm plug. We assumed that females were always receptive because in this species mating occurs year-round and even with ovigerous females. The majority of experimental matings was successful suggesting that females were attracted to males.

\section{Data analyses and statistics}

To test seasonal variation in VSI, a one-way ANOVA was performed and subsequently a Tukey test was used for multiple comparisons of treatment means ( $\mathrm{n}=7$ in winter and spring each, $\mathrm{n}=5$ in summer and $n=6$ in autumn).

To estimate morphometric size at maturity in males $(n=62)$ a piecewise linear regression model with a breakpoint was used. Parameters were calculated by the least squares method using the Levenberg-Marquardt algorithm (Gill and Murray, 1978) in STATISTICA 7.0 (StatSoft, Hamburg). The independent variable was male CL and the dependent variable was height of the left chela (if absent, right was used). The breakpoint is considered a morphometric indicator of maturity (Somerton, 1980). For model selection (one or two regression lines) we used the test proposed by Somerton (1980):

$$
F=\frac{\frac{\left(R S S_{1}-R S S_{2}\right)}{2}}{\frac{R S S_{2}}{(n-4)}}
$$

where $R S S_{1}$ and $R S S_{2}$ are the residual sums of squares models with a single and two lines fit to the data, respectively, and $n$ is the number of data points. The test statistic is distributed as $F$ with 2 and n - 4 degrees of freedom.

To detect differences between adolescent and adult males in duration of copulation and pre- and post-copulatory behavior, as well as ejaculate delivery per receptacle, unpaired $t$-tests were performed $(\mathrm{n}=$ 6 pairs per ontogenetic stage). To detect differences in ejaculate delivery between non-ovigerous $(n=13$ of which 5 and 8 males were adolescent and adult, respectively) and ovigerous ( $\mathrm{n}=11$ of which 4 and 7 males were adolescent and adult, respectively) females an unpaired $t$-test was performed. To identify which variable or variables best describe the variation in ejaculate transfer to females ( $n=24$ pairs), linear models (LM) were performed. Tested variables include CL of female, CL of male, difference between female and male CL (\%), VDW after mating, old ejaculate stored in seminal receptacle of female, female nonovigerous or ovigerous, male ontogenetic stage and dry weight of the ovaries. The Akaike information criterion (AIC) was used to choose the model which explained best the variation in ejaculate transferred. Linear regressions were performed for each male ontogenetic stage to test the relationship between $\mathrm{CL}$ of the female and ejaculate delivered per receptacle, as well as percentage of VDW delivered in one mating, respectively.

All data were checked for normality using the Shapiro-Wilk test. The Bartlett test was applied to check for variance homogeneity. All statistical analyses were performed using the software R version 3.4 ( $R$ Core Team, 2017), except for estimation of size at morphometric maturity.

\section{ResULtS}

\section{Seasonal pattern of male reproductive investment}

The VSI of adult males showed significant seasonal variation, with a decrease in the index in spring (oneway ANOVA, season: $F_{3,21}=3.53, p=0.033$ ) (Fig. 2).

\section{Determination of adolescent and adult males}

Two phase lines described the relationship between $\mathrm{CL}$ and male chela height better than a single line (Fig. 3). The model was presented as $\mathrm{y}=-8.1102+$ $0.355799 \times \mathrm{CL}+0.159701 \times(\mathrm{CL}-96.4999)$ $\times(\mathrm{CL}>96.4999) ;\left(R^{2}=0.9097\right.$; variance explained: $82.7 \%)$ corresponding to $Q H=$ constant + slope $I \times$ $\mathrm{CL}+$ slope II $\times(\mathrm{CL}$ - breakpoint $) \times(\mathrm{CL}>$ breakpoint $)$. Size at which $50 \%$ of males reached morphometric maturity was $96.4 \pm 3.8 \mathrm{~mm} \mathrm{CL}$ (values in the Results section correspond to means \pm standard errors). Crabs equal to or greater than $96.4 \mathrm{~mm}$ CL were considered as morphometrically mature (i.e., adults) and smaller 
as adolescents. The smallest male that engaged in successful mating (i.e., functional sexual maturity) measured $87.3 \mathrm{~mm}$ CL. Vasa deferentia were visible in all males upon dissection.

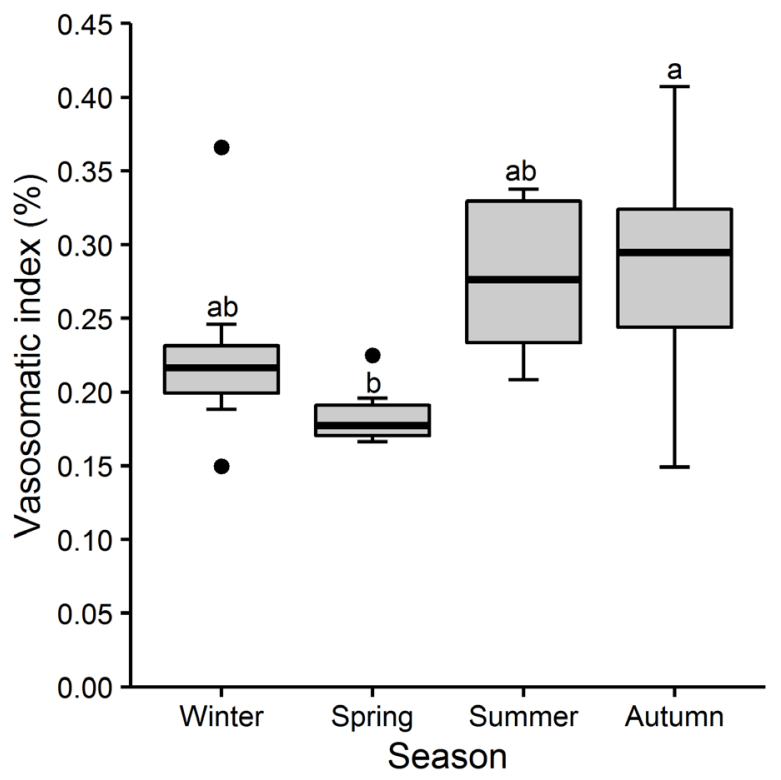

Figure 2. Box plot of seasonal vasosomatic index (VSI) of Taliepus dentatus from Los Molinos Bay, Chile. Boxes: interquartile range of the data (first quartile, median and third quartile). Whiskers: the values that extend to 1.5 times the interquartile range. Circles: outliers. Letters indicate significant differences $(p<0.05)(\mathrm{Rv} 3.4)$.

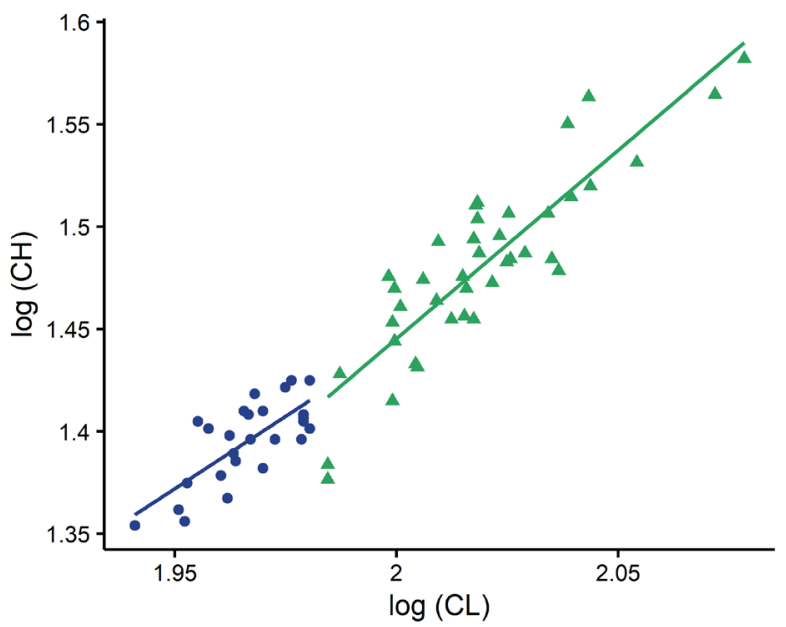

Figure 3. Regression lines of the $\log _{10}$ chela height $(\mathrm{CH})$ vs. $\log _{10}$ carapace length $(\mathrm{CL})$ for adolescent $(\mathrm{y}=1.414-1.386 \mathrm{x})$ and adult males $(\mathrm{y}=1.842-2.240 \mathrm{x})$ in Taliepus dentatus. Adolescent and adult males are indicated by dots and triangles, respectively ( $\mathrm{R} v 3.4)$.

\section{Mating behavior}

A brief pre-copulatory mate guarding was performed in all pairs and lasted, on average, 0.40 $\pm 0.07 \mathrm{~h}$ (range: $0.25-0.73 \mathrm{~h}$ ) for adolescent males and $0.48 \pm 0.27 \mathrm{~h}$ (range: $0.13-1.86 \mathrm{~h}$ ) for adult males. Duration of pre-copulatory guarding did not differ between adolescent and adult males (twotailed unpaired $t$-test, $t$-value $=-0.29, p=0.78)$. Precopulatory guarding was characterized by the male grasping the female in the rostral region using his chelae and/or caging the female between his legs while being in a rostrum-to-rostrum position.

Then, copulation occurred in the sternum-tosternum position (Fig. 1B). The pleon of the male and female were extended. Copulation lasted longer in adult males (mean $=1.98 \pm 0.35 \mathrm{~h}$; range: $0.83-2.96 \mathrm{~h}$ ) than in adolescent males (mean $=1.26 \pm 0.16 \mathrm{~h}$; range: $0.83-1.93 \mathrm{~h}$ ), however, the difference was not significant (two-tailed unpaired $t$-test, $t$-value $=-1.83$, $p=0.09$ ) (Fig. 4A). Repeated mating was observed in adolescent and adult males in 4 of 6 and in 2 of 6 pairs, respectively, whereby the maximum mating frequency observed in these pairs was just twice.

After copulation, a majority of adolescent ( 5 of 6 pairs) and adult males ( 4 of 6 pairs) engaged in post-copulatory guarding, which lasted, on average, $2.40 \pm 1.85 \mathrm{~h}$ (range: $0.00-11.50 \mathrm{~h}$ ) and $2.62 \pm 1.52$ h (range: $0.00-7.50 \mathrm{~h}$ ), respectively. Duration of post-copulatory guarding did not differ between adolescent and adult males (two-tailed unpaired $t$-test, $t$-value $=-0.09, p=0.93)$. Post-copulatory guarding occurred in the rostrum-to-rostrum position, which was characterized by the male grasping the female or holding the female with one chela and carrying her around. In contrast, no post-copulatory guarding was observed (i.e., pairs separated immediately after copulation) in one and two pairs containing adult and adolescent males, respectively.

\section{Ejaculate allocation}

Adult males transferred a significantly larger quantity of ejaculate to females than adolescent males (two-tailed unpaired $t$-test, $t$-value $=-3.55, p=0.005$ ) (Fig. 4B). Total VDW (i.e., doubling left vas deferens) before mating in adolescent and adult males was 144.3 
$\pm 16.8 \mathrm{mg}$ (range: $72.8-242.0 \mathrm{mg}$ ) and $184.5 \pm 13.5$ mg (range: 107.0-292.8 mg), respectively. Total VDW after mating in adolescent and adult males was 90.5 $\pm 12.0 \mathrm{mg}$ (range: $68.4-167.8 \mathrm{mg}$ ) and $114.7 \pm 10.5$ mg (range: $71.0-218.4 \mathrm{mg}$ ), respectively. All females had ejaculate stored in the left, non-refreshed, seminal receptacle prior to experimental matings $($ mean $=51.0$
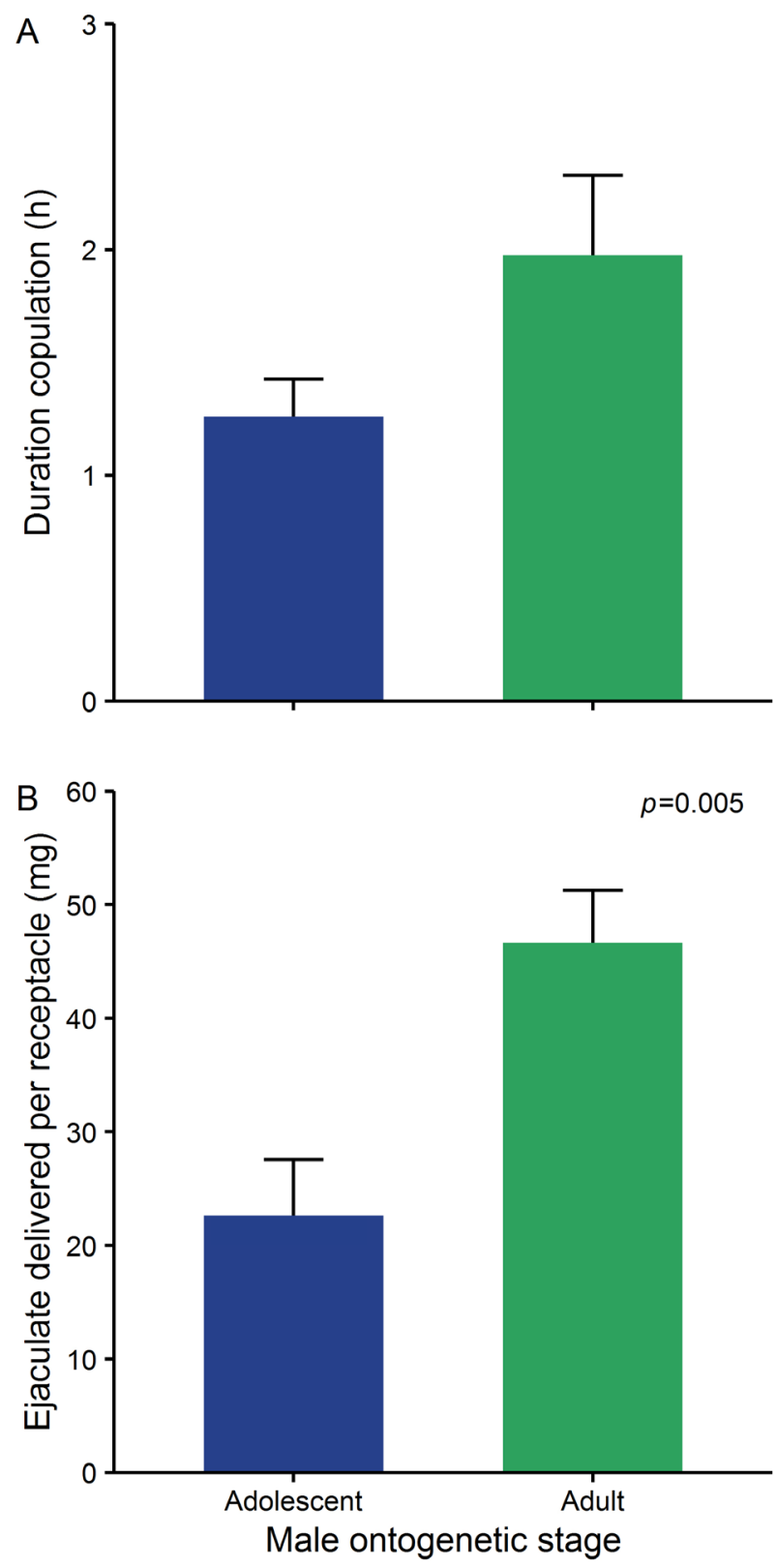

Figure 4. Mating characteristics of Taliepus dentatus of different male ontogenetic stages. (A) Average total duration of copulation of experimental mating pairs $(n=6$ pairs per ontogenetic stage). (B) Average ejaculate delivery per female seminal receptacle (n $=6$ pairs per ontogenetic stage). $P$-value is indicated. Values are means + SE (Rv 3.4). $\pm 5.8 \mathrm{mg}$; range: $18.3-126.1 \mathrm{mg}$ ). Mean fresh ejaculate weight received by females in one receptacle was not different between non-ovigerous $(32.1 \pm 3.6 \mathrm{mg})$ and ovigerous females $(33.3 \pm 3.7 \mathrm{mg})$ (two-tailed unpaired $t$-test, $t$-value $=-0.16, p=0.86)$, disregarding the male ontogenetic stage. A sperm plug was not detected in any female.

The model selected by the AIC which best explained the ejaculate amount received by females of both adolescent and adult males only included CL of females and the linear model indicated that female CL significantly influenced the amount of ejaculate delivered per seminal receptacle (equation: ejaculate delivered per receptacle $=-86.542+1.448 \times\left(\mathrm{CL}_{\mathrm{F}}\right)$; $\left.R^{2}=0.28, F_{1,22}=9.926, p=0.004\right)$ (Tab. 1). Including only adolescent males, ejaculate delivered per seminal receptacle showed a significant linear relationship with female CL and a better fit (equation: ejaculate delivered per receptacle $=-134.007+2.048 \times\left(\mathrm{CL}_{\mathrm{F}}\right)$; $R^{2}=0.92, F_{1,7}=89.45, p<0.001$ ) (Fig. 5). In adult males ejaculate delivery per seminal receptacle was not related to female CL (non-significant relationship).

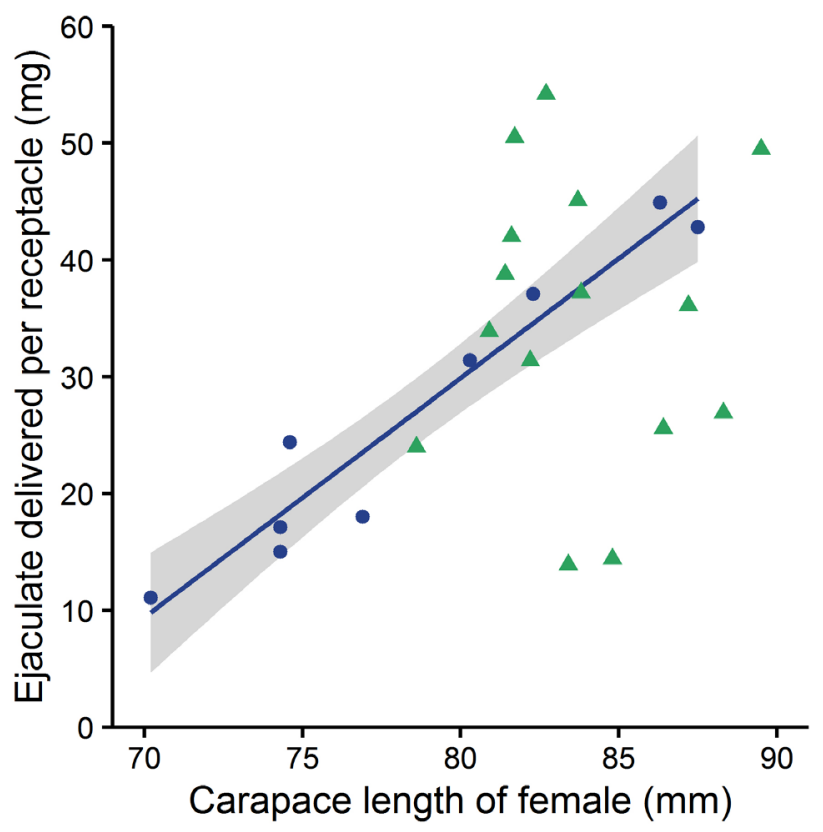

Figure 5. Relationship between ejaculate delivered per female seminal receptacle and carapace length of the female in Taliepus dentatus. Adolescent and adult males are indicated by dots and triangles, respectively. Line: linear fit of adolescent males (significant regression). Grey area: confidence interval ( $\pm 95 \%$ ) of the fit. Data correspond to experimental matings under equal sex ratio ( $\mathrm{R} v 3.4)$. 
Table 1. Model building results of the linear model of ejaculate weight delivered per seminal receptacle in Taliepus dentatus. Independent variables include: $C L_{\mathrm{F}}$ : carapace length of female; $C L_{\mathrm{M}}$ : carapace length of male; $C L_{\mathrm{F}: \mathrm{M}}$ : difference between female and male carapace length (\%); VDW $W_{\text {after }}$ : vasa deferentia dry weight after mating; $E_{\text {old }}$ : ejaculate stored in seminal receptacle of female; OVI: female non-ovigerous or ovigerous; ODW: ovaries dry weight; and ONT: male ontogenetic stage (i.e., adolescent or adult). Degrees of freedom $(d f)$, residual deviance (Resid. Deviance), residual degrees of freedom (Resid. $d f$ ), and Akaike information criterion (AIC) are given. Bold: best model.

\begin{tabular}{|c|c|c|c|c|}
\hline Variables & $d f$ & Resid. deviance & Resid. $d f$ & AIC value \\
\hline$C L_{\mathrm{F}}+C L_{\mathrm{M}}+C L_{\mathrm{F}: \mathrm{M}}+E_{\mathrm{old}}+O V I+O D W+V D W_{\text {after }}+O N T$ & & 1947.1 & 15 & 123.5 \\
\hline$C L_{\mathrm{F}}+C L_{\mathrm{M}}+C L_{\mathrm{F}: \mathrm{M}}+E_{\mathrm{old}}+O V I+O D W+V D W_{\mathrm{after}}$ & 1 & 1953.7 & 16 & 121.6 \\
\hline$C L_{\mathrm{F}}+C L_{\mathrm{M}}+C L_{\mathrm{F}: \mathrm{M}}+E_{\mathrm{old}}+O V I+O D W$ & 1 & 2039.5 & 17 & 120.6 \\
\hline$C L_{\mathrm{F}}+C L_{\mathrm{F}: \mathrm{M}}+E_{\mathrm{old}}+O V I+O D W$ & 1 & 2098.1 & 18 & 119.3 \\
\hline$C L_{\mathrm{F}}+E_{\mathrm{old}}+O V I+O D W$ & 1 & 2228.3 & 19 & 118.7 \\
\hline$C L_{\mathrm{F}}+E_{\mathrm{old}}+\mathrm{OVI}$ & 1 & 2321.0 & 20 & 117.7 \\
\hline$C L_{\mathrm{F}}+E_{\text {old }}$ & 1 & 2449.2 & 21 & 117.0 \\
\hline$C L_{\mathrm{F}}$ & 1 & 2608.9 & 22 & 116.5 \\
\hline
\end{tabular}

In adolescent crabs, the percentage of initial VDW transferred during mating and the CL of the female showed a significant, but weaker, fit to a linear model (equation: percentage of VDW delivered in one mating $=-65.823+1.307 \times\left(C L_{\mathrm{F}}\right) ; R^{2}=0.44, F_{1,7}=7.228$, $p=0.031$ ); while in adult males no such relationship was detected (Fig. 6).

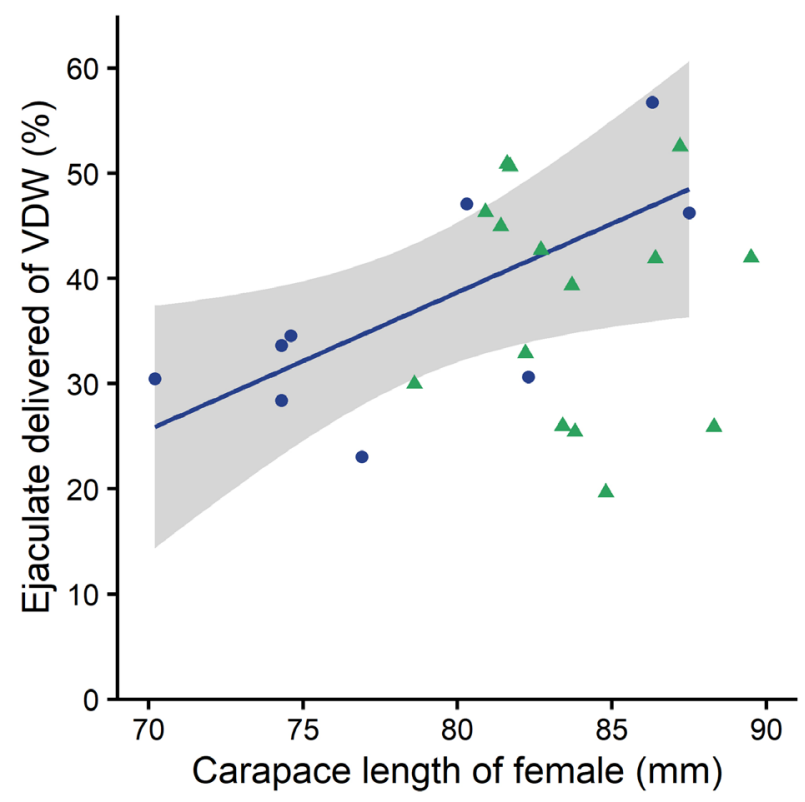

Figure 6. Relationship between percentage of initial vasa deferentia dry weight (VDW) transferred during mating and carapace length of the female in Taliepus dentatus. Adolescent and adult males are indicated by dots and triangles, respectively. Line: linear fit of adolescent crabs (significant regression). Grey area: confidence interval $( \pm 95 \%)$ of the fit $(\mathrm{R} v 3.4)$.

\section{Discussion}

The vasa deferentia of $T$. dentatus are remarkable structures inside the cephalothoracic cavity of male crabs. The VSI showed some seasonal fluctuations, but the laboratory matings were observed nearly all months of the year, indicating a continuous reproductive pattern, but with a greater intensity in winter and spring. The seasonal means of the VSI in T. dentatus ranged from 0.18 to $0.28 \%$. The VSI in Metacarcinus edwardsii (Bell, 1835) and Lithodes santolla (Molina, 1782) are $0.14 \%$ (recalculated according to Pardo et al., 2015) and $0.047 \%$ (Pretterebner et al., 2019), respectively, but can also be as large as approximately $6 \%$, as in Homalaspis plana (H. Milne Edwards, 1834) (Pardo et al., 2019). Compared with these other species, the VSI of T. dentatus was intermediate and suggests that the kelp crab invests a significant part of its energy in reproductive development, constantly producing large quantities of seminal material and recovering it relatively fast after mating (Pretterebner and Pardo, 2020). The VSI has been calculated for other crustacean species, but based on wet weight and the entire body (with legs and chelae) weight (reviewed by Sainte-Marie, 2007). This makes a comparison with the VSI based on dry weight and body weight only (less legs and chelae), impossible. In fact, Sainte-Marie (2007) recommended the use of the body weight without legs and chelae to increase accuracy of the VSI in crustaceans. 
In T. dentatus mating and molting were not linked and occurred during the female "hard-shelled" stage. This indicates the strategy of determinate growth in females, which predominates in majoids (Hartnoll, 1963; Jones and Hartnoll, 1997; McLay and López Greco, 2011). Similarly, females of several other spider crabs mate predominately "hard-shelled" such as Inachus dorsettensis (Pennant, 1777) (Jones and Hartnoll, 1997), L. emarginata (see Hinsch, 1968), L. spinosa (see Sal Moyano and Gavio, 2012) and Maja squinado (Herbst, 1788) (González-Gurriarán et al., 1998). In other species in the superfamily Majoidea, such as C. opilio (Elner and Beninger, 1995) and Chionoecetes bairdi Rathbun, 1924 (Adams and Paul, 1983; Paul, 1984), which both belong to the family Oregonidae, the first female mating occurs post-molt (i.e., soft-shelled) and subsequently matings in the "hard-shelled" stage.

The intensity of reproduction in T. dentatus seems particularly high as males completed matings with non-ovigerous and ovigerous females. The results also indicate that these females were always receptive to mating after the terminal molt, and that no sperm plug was formed to prevent additional males from mating. In some other majoids, females are also able to mate any time (McLay and López Greco, 2011). In species of the family Epialtidae such as L. emarginata (see Hinsch, 1968) and Pugettia producta (Randall, 1840) (Knudsen, 1964) mating with ovigerous females have also been registered. Generally, this behavior has been reported in various species of the superfamily Majoidea (Berry and Hartnoll, 1970; Sainte-Marie et al., 1997; 1999; González-Gurriarán et al., 1998; Carmona-Suárez, 2003) and in some species of Portunidae (Norman, 1996; Norman et al., 1997; 1999) and Ocypodidae (Goshima et al., 1996; Jennings et al., 2000). Copulation with ovigerous females has been mainly reported in females with eggs in late developmental stages (Norman, 1996; Norman et al., 1997; 1999; González-Gurriarán et al., 1998). Copulation with females that are carrying eggs may have implicit risks of egg loss for females and in $T$. dentatus this may be compensated for by producing broods year-round.

Males of T. dentatus that still had not reached morphometric maturity (i.e., non-terminally-molted) were able to engage successfully in matings, which indicates that functional sexual maturity (i.e., the ability to copulate and transfer ejaculate; Elner and Beninger, 1989; Sainte-Marie et al., 2008) was attained prior to morphometric maturity. Accordingly, this corroborates that two types of males readily mated, but at different ontogenetic stages.

The behavior of pre- and post-copulatory guarding and copulation of $T$. dentatus was similar to previous descriptions in related crabs (Hartnoll, 1997; Sal Moyano and Gavio, 2012). Brief pre-copulatory guarding was displayed in both, adolescent and adult males, lasting on average 0.4 and $0.48 \mathrm{~h}$, respectively. Post-copulatory mate guarding was present in the majority of both, adolescent and adult males, lasting on average 2.4 and $2.62 \mathrm{~h}$, respectively. However, this behavior was flexible, and highly variable in duration, in both male ontogenetic stages. Post-copulatory guarding is present in most of the majoid species studied such as in L. emarginata (see Laufer and Ahl, 1995), L. spinosa (see Sal Moyano and Gavio, 2012), I. dorsettensis (see Jones and Hartnoll, 1997) and C. opilio (see Sainte-Marie et al., 1997), whereas it is absent in M. squinado (see González-Gurriarán et al., 1998). Post-copulatory guarding differs between distinct ontogenetic stages in C. opilio (see Sainte-Marie et al., 1997), L. emarginata (see Sagi et al., 1994) and L. spinosa (see Sal Moyano and Gavio, 2012) and is commonly absent in adolescents, but found in adults.

In the present study, duration of copulation, ejaculate quantity received by females and frequency of repeated matings varied with male ontogenetic stage: adolescents delivered less ejaculate in repeated short copulations, whereas adults usually transferred more ejaculate in a single extended copulation. Similarly, in C. opilio the mating behavior of the two male developmental stages are characterized by abbreviated pre-copulatory guarding, several brief copulations and optional post-copulatory guarding in adolescents $v s$. pronounced pre- and post-copulatory guarding behavior and one long copulation in adults (Sainte-Marie et al., 1997). In L. spinosa the two male morphotypes have a similar duration of copulation but differ in duration of both pre- and post-copulatory guarding (Sal Moyano and Gavio, 2012). In this study, 
duration of both pre- and post-copulatory behaviors did not differ between male ontogenetic stages.

The ability of males to adjust the ejaculate amount proportionally to female size was highly evident in adolescent males, which was reflected in a good fit of the significant relationship between ejaculate delivery and female size. Complementary to the absolute values of ejaculate delivery, adolescent males scaled the percentage of initial VDW transferred during mating to the CL of the female, which was reflected in a significant relationship, but with a weaker fit. Absolute (i.e., amount of ejaculate delivery) and relative values (i.e., \% of VDW delivered) of ejaculate allocation support the case that adolescent males were able to tailor ejaculate delivery in relation to female size. Consequently, this strongly suggests that in adolescent males ejaculate allocation was strategic with regard to female size. This indicates that the alternative explanation, that adolescent males expend ejaculate arbitrarily, simply according to their available seminal reserves, and as a result of a limited capacity to deliver ejaculate, is unlikely. Further, the remaining VDW after mating was not selected by the linear model to explain ejaculate delivery.

In contrast, female size-dependent ejaculate allocation (the amount of ejaculate and \% of VDW delivered) was not detected in adult males. In adult males ejaculate allocation was independent of the reproductive variables tested. Adolescent males prudently allocated their seminal reserves in response to female size (a proxy of female fecundity) and on average invested less ejaculate in each female than adult males. This suggests that a prudent strategic allocation of ejaculate according to the reproductive return of the female might be relatively more important for adolescent males than for adult males. Probably, in T. dentatus ejaculate allocation patterns dependent on ontogenetic stage may be explained by distinct resource investment to different requirements. Adolescent males still have not reached their terminal molt and are still in the growth process. Their limited surplus energy reserves may be partitioned between maintenance, production of gametes and somatic growth, which may be a trade-off between investing surplus energy to distinct requirements. This may highlight the importance for adolescent males to economically and strategically use their seminal material. In adult males which have ceased to grow after the terminal molt, it may not be necessary to invest surplus energy into somatic growth. Their surplus energy may solely be assigned to reproduction, which emphasizes the irrelevance of a judicious ejaculate allocation for adults. In comparison in another decapod species, such as Rhynchocinetes typus H. Milne Edwards, 1837, males of the 'robustus' ontogenetic stage (i.e., terminal molt stage) apparently allocate spermatophores strategically to female size, but males of the 'adolescent' stage do not (Hinojosa and Thiel, 2003). Possibly the risk of displacement during mating is much higher in R. typus, and so the adolescent males have to be very fast and transfer spermatophores without first sizing up the female because of the high risk of displacement by dominant males. In opposition, in T. dentatus, the risk of displacement during copulation is probably rather low and adolescent males have enough time to evaluate the female and are then able to allocate strategically. This comparison is interesting, but it concerns a shrimp in which spermatophores are attached by the male externally to the ventral side of the female abdomen (Correa et al., 2000), and a brachyuran crab in which females possess seminal receptacles to store ejaculate internally. More evidence concerning strategic ejaculate allocation is needed from species in which several stages of males participate in the copulation process.

Sainte-Marie et al. (1997) suggested that the two contrasting mating behaviors according to male ontogenetic stages (several short copulations vs. single long copulation) in C. opilio represented distinct mating tactics, resembling the "re-mater" and "resistor" types described in insects. Alternative mating tactics have been reported in a wide variety of crustacean species (Shuster, 2008), including spider crab (Majoidea) species, in which distinct patterns of mating behavior in different morphotypes, associated with male ontogenetic stage within single populations, have been demonstrated (Laufer and Ahl, 1995; SainteMarie et al., 1997; Sal Moyano and Gavio, 2012). The morphological differences between morphotypes are based on the relationship between the size of chelae and body (Homola et al., 1991; Comeau and Conan, 1992; Stevens et al., 1993; Sampedro et al., 1999; Mura et al., 2005; Sal Moyano et al., 2010), which can exist 
as a result of sexual maturity processes associated with the specific growth pattern. Our findings suggest that the distinct mating tactics of the two different male ontogenetic stages in $T$. dentatus may be modulated by the capacity of seminal material production.

\section{ACKNOWLEDGEMENTS}

We especially thank Dr. Martin Thiel and an anonymous reviewer for the revision and detailed comments, which have helped to improve the manuscript. Thanks are also extended to the workers from the Laboratorio Costero de Recursos Acuáticos de Calfuco. Funding was provided by the Fondo Nacional de Desarrollo Científico y Tecnológico (FONDECYT 1150388) and the Fondo de Financiamiento de Centros de Investigación en Áreas Prioritarias (FONDAP IDEAL 15150003). KP was supported by a Chilean $\mathrm{PhD}$ scholarship from the Comisión Nacional de Investigación Científica y Tecnológica (CONICYT scholarship number 63140248).

\section{References}

Adams, A.E. and Paul, A.J. 1983. Male parent size, sperm storage and egg-production in the crab Chionoecetes bairdi (Decapoda, Majidae). International Journal of Invertebrate Reproduction, 6: 181-187.

Baldanzi, S.; Storch, D.; Navarrete, S.A.; Graeve, M. and Fernández, M. 2018. Latitudinal variation in maternal investment traits of the kelp crab Taliepus dentatus along the coast of Chile. Marine Biology, 165: 1-12.

Berry, P.F. and Hartnoll, R.G. 1970. Mating in captivity of the spider crab Pleistacantha moseleyi (Miers) (Decapoda, Majidae). Crustaceana, 19: 213-215.

Brockerhoff, A.M. and McLay, C.L. 2005. Mating behaviour, female receptivity and male-male competition in the intertidal crab Hemigrapsus sexdentatus (Brachyura: Grapsidae). Marine Ecology Progress Series, 290: 179-191.

Carmona-Suárez, C.A. 2003. Reproductive biology and relative growth in the spider crab Maja crispata (Crustacea: Brachyura: Majidae). Scientia Marina, 67: 75-80.

Carreja, B.; Fernández, M. and Agusti, S. 2016. Joint additive effects of temperature and UVB radiation on zoeae of the crab Taliepus dentatus. Marine Ecology Progress Series, 550: 135-145.

Comeau, M. and Conan, G.Y. 1992. Morphometry and gonad maturity of male snow crab, Chionoecetes opilio. Canadian Journal of Fisheries and Aquatic Sciences, 49: 2460-2468.

Conan, G.Y. and Comeau, M. 1986. Functional maturity and terminal molt of male snow crab, Chionoecetes opilio. Canadian Journal of Fisheries and Aquatic Sciences, 43: 1710-1719.
Corgos, A. and Freire, J. 2006. Morphometric and gonad maturity in the spider crab Maja brachydactyla: a comparison of methods for estimating size at maturity in species with determinate growth. Journal of Marine Science, 63: 851-859.

Correa, C.; Baeza, J.A.; Dupré, E.; Hinojosa, I.A. and Thiel, M. 2000. Mating behavior and fertilization success of three ontogenetic stages of male rock shrimp Rhynchocinetes typus (Decapoda: Caridea). Journal of Crustacean Biology, 20: 628-640.

Dewsbury, D.A. 1982. Ejaculate cost and male choice. The American Naturalist, 119: 601-610.

Elner, R.W. and Beninger, P.G. 1989. Comment on functional maturity in small male snow crab (Chionoecetes opilio): sizing up the evidence. Canadian Journal of Fisheries and Aquatic Sciences, 46: 2037-2039.

Elner, R.W. and Beninger, P.G. 1995. Multiple reproductive strategies in snow crab Chionoecetes opilio: physiological pathways and behavioural plasticity. Journal of Experimental Marine Biology and Ecology, 193: 93-112.

Fagetti, E. and Campodonico, I. 1971. Desarrollo larval en el laboratorio de Taliepus dentatus (Milne-Edwards) (Crustacea Brachyura: Majidae, Acanthonychinae). Revista Biologia Marina, 14: 1-14.

Gill, P.E. and Murray, W. 1978. Algorithms for the solution of the nonlinear least-squares problem. SIAM Journal on Numerical Analysis, 15: 977-992.

González-Gurriarán, E.; Fernández, L.; Freire, J. and Muiño, R. 1998. Mating and role of seminal receptacles in the reproductive biology of the spider crab Maja squinado (Decapoda, Majidae). Journal of Experimental Marine Biology and Ecology, 220: 269-285.

Goshima, S.; Koga, T. and Murai, M. 1996. Mate acceptance and guarding by male fiddler crabs Uca tetragonon (Herbst). Journal of Experimental Marine Biology and Ecology, 196: 131-143.

Gosselin, T.; Sainte-Marie, B. and Bernatchez, L. 2003. Patterns of sexual cohabitation and female ejaculate storage in the American lobster (Homarus americanus). Behavioral Ecology and Sociobiology, 55: 151-160.

Hartnoll, R.G. 1963. The biology of Manx spider crabs. Journal of Zoology, 141: 423-496.

Hartnoll, R.G. 1984. Strategies of crustacean growth. Australian Museum Memoir, 18: 121-131.

Hartnoll, R.G. 2001. Growth in Crustacea - twenty years on. Hydrobiologia, 449: 111-122.

Hines, A.H.; Jivoff, P.R.; Bushmann, P.J.; van Montfrans, J.; Reed, S.A.; Wolcott, D.L. and Wolcott, T.G. 2003. Evidence for sperm limitation in the blue crab, Callinectes sapidus. Bulletin of Marine Science, 72: 287-310.

Hinojosa, I. and Thiel, M. 2003. Somatic and gametic resources in male rock shrimp, Rhynchocinetes typus: effect of mating potential and ontogenetic male stage. Animal Behaviour, 66: 449-458.

Hinsch, G.W. 1968. Reproductive behavior in the spider crab, Libinia emarginata (L.). Biological Bulletin, 135: 273-278.

Homola, E.; Sagi, A. and Laufer, H. 1991. Relationship of claw form and exoskeleton condition to reproductive system size and methyl farnesoate in the male spider crab, Libinia emarginata. Invertebrate Reproduction and Development, 20: 219-225. 
Jennings, A.C.; McLay, C.L. and Brockerhoff, A.M. 2000. Mating behaviour of Macrophthalmus hirtipes (Brachyura: Ocypodidae). Marine Biology, 137: 267-278.

Jivoff, P. 2003. A review of male mating success in the blue crab, Callinectes sapidus, in reference to the potential for fisheriesinduced sperm limitation. Bulletin of Marine Science, 72: 273-286.

Jones, D.R. and Hartnoll, R.G. 1997. Mate selection and mating behaviour in spider crabs. Estuarine, Coastal and ShelfScience, 44: 185-193.

Kendall, M.S.; Wolcott, D.L.; Wolcott, T.G. and Hines, A.H. 2002. Influence of male size and mating history on sperm content of ejaculates of the blue crab Callinectes sapidus. Marine Ecology Progress Series, 230: 235-240.

Knudsen, J.W. 1964. Observations of the mating process of the spider crab Pugettia producta (Majidae, Crustacea). Bulletin of the Southern California Academy of Science, 63: 38-41.

Laufer, H. and Ahl, J. 1995. Mating behavior and methyl farnesoate levels in male morphotypes of the spider crab, Libinia emarginata (Leach). Journal of Experimental Marine Biology and Ecology, 193: 15-20.

McLay, C.L. 2015. Moulting and growth in Brachyura. p. 245316. In: P. Castro; P.J.F. Davie; D. Guinot; F.R. Schram and J.C. von Vaupel Klein (eds), Treatise on zoology - anatomy, taxonomy, biology. The Crustacea, Volume 9C, Leiden/ Boston, Koninklijke Brill NV.

McLay, C.L. and López Greco, L.S. 2011. A hypothesis about the origin of sperm storage in the Eubrachyura, the effects of seminal receptacle structure on mating strategies and the evolution of crab diversity: how did a race to be first become a race to be last? Zoologischer Anzeiger, 250: 378-406.

Mura, M.; Orrú, F. and Cau, A. 2005. Size at sexual maturity of the spider crab Anamathia rissoana (Decapoda: Majoidea) from the Sardinian Sea. Journal of Crustacean Biology, 25: 110-115.

Norman, C.P. 1996. Reproductive biology and evidence for hard-female mating in the brachyuran crab Thalamita sima (Portunidae). Journal of Crustacean Biology, 16: 656-662.

Norman, C.P.; Hirano, Y.J. and Miyazaki, T. 1997. Hard-female mating in the brachyuran crab Thalamita prymna (Portunidae). Crustacean Research, 26: 62-69.

Norman, C.P.; Nuka, T. and Miyazaki, T. 1999. Mating behavior in Thalamita picta (Brachyura: Portunidae) and comparisons with congeneric species. Crustacean Research, 28: 16-23.

Pardo, L.M.; Riveros, M.P.; Chaparro, O.R. and Pretterebner, K. 2018. Ejaculate allocation in Brachyura: what do males of Metacarcinus edwardsii respond to? Aquatic Biology, 27: 25-33.

Pardo, L.M.; Riveros, M.P.; Fuentes, J.P. and López Greco, L. 2013. Functional morphology of the seminal receptacle in the crab Metacarcinus edwardsii. Invertebrate Biology, 132: 386-393.

Pardo, L.M.; Rosas, Y.; Fuentes, J.P.; Riveros, M.P. and Chaparro, O.R. 2015. Fishery induces sperm depletion and reduction in male reproductive potential for crab species under malebiased harvest strategy. PLoS ONE, 10: 1-16.

Pardo, L.M.; Zara, F.J.; Riveros, M.P.; Paschke, K.; Pretterebner, K. and Mantelatto, F.L. 2019. Integrative depiction of the male reproductive system of the commercial purple crab Homalaspis plana (Platyxanthidae): Structure and function. Journal of Morphology, 1-13.
Paul, A.J. 1984. Mating frequency and viability of stored sperm in the tanner crab Chionoecetes bairdi (Decapoda, Majidae). Journal of Crustacean Biology, 4: 375-381.

Pretterebner, K. and Pardo, L.M. 2020. All or nothing: Switch to high current reproductive investment under risk of starvation in male kelp crab. Ecology and Evolution, 00: 1-9.

Pretterebner, K.; Pardo, L.M. and Paschke, K. 2019. Temperaturedependent seminal recovery in the southern king crab Lithodes santolla. Royal Society open science, 6: 181700.

R Core Team. 2017. R: a language and environment for statistical computing. R foundation for statistical computing, Vienna, Austria. Available at https://www.R-project.org/. Accessed on 15 March 2020.

Retamal, M.; Aedo, G.; Suárez, C.; Montecinos, S.; Gacitúa, S.; Pedraza, M. and Arana, P. 2009. Estado actual del conocimiento de las principales especies de jaibas a nivel nacional. Informe Final del Fondo de Investigacion Pesquera n ${ }^{\circ}$ 2007-39. Concepción, Universidade de Concepción, Departamento de Oceanografía, vii+237p. Available at https: / / www.subpesca. cl/fipa/613/articles-89207_informe_final.pdf. Accessed on 15 March 2020.

Rondeau, A. and Sainte-Marie, B. 2001. Variable mate-guarding time and sperm allocation by male snow crabs (Chionoecetes opilio) in response to sexual competition, and their impact on the mating success of females. Biological Bulletin, 201: 204-217.

Rubolini, D.; Galeotti, P.; Ferrari, G.; Spairani, M.; Bernini, F. and Fasola, M. 2006. Sperm allocation in relation to male traits, female size, and copulation behaviour in freshwater crayfish species. Behavioral Ecology and Sociobiology, 60: 212-219.

Sagi, A.; Ahl, J.S.B.; Danaee, H. and Laufer, H. 1994. Methyl farnesoate levels in male spider crabs exhibiting active reproductive behavior. Hormones and Behavior, 28: 261-272.

Sainte-Marie, B. 2007. Sperm demand and allocation in decapod crustaceans. p. 191-210. In: J.E. Duffy and M. Thiel (eds), Evolutionary ecology of social and sexual systems: crustaceans as model organisms, New York, Oxford University Press.

Sainte-Marie, B.; Gosselin, T.; Sévigny, J.M. and Urbani, N. 2008. The snow crab mating system: opportunity for natural and unnatural selection in a changing environment. Bulletin of Marine Science, 83: 131-161.

Sainte-Marie, B. and Lovrich, G.A. 1994. Delivery and storage of sperm at first mating of female Chionoecetes opilio (Brachyura: Majidae) in relation to size and morphometric maturity of male parent. Journal of Crustacean Biology, 14: 508-521.

Sainte-Marie, B.; Raymond, S. and Brêthes, J.-C. 1995. Growth and maturation of the benthic stages of male snow crab, Chionoecetes opilio (Brachyura: Majidae). Canadian Journal of Fisheries and Aquatic Sciences, 52: 903-924.

Sainte-Marie, B.; Sévigny, J.-M. and Carpentier, M. 2002. Interannual variability of sperm reserves and fecundity of primiparous females of the snow crab (Chionoecetes opilio) in relation to sex ratio. Canadian Journal of Fisheries and Aquatic Sciences, 59: 1932-1940.

Sainte-Marie, B.; Sévigny, J.-M. and Gauthier, Y. 1997. Laboratory behavior of adolescent and adult males of the snow crab (Chionoecetes opilio) (Brachyura: Majidae) mated noncompetitively and competitively with primiparous 
females. Canadian Journal of Fisheries and Aquatic Sciences, 54: 239-248.

Sainte-Marie, B.; Urbani, N.; Sévigny, J.M.; Hazel, F. and Kuhnlein, U. 1999. Multiple choice criteria and the dynamics of assortative mating during the first breeding period of female snow crab Chionoecetes opilio (Brachyura, Majidae). Marine Ecology Progress Series, 181: 141-153.

Sal Moyano, M.P. and Gavio, M.A. 2012. Comparison of mating behavior and copulation in male morphotypes of the spider crab Libinia spinosa (Brachyura: Majoidea: Epialtidae). Journal of Crustacean Biology, 32: 31-38.

Sal Moyano, M.P.; Gavio, M.A. and Maggi, M.D. 2010. Morphometric and gonad maturity of the spider crab Libinia spinosa (Crustacea: Brachyura: Majoidea: Epialtidae) in Argentina. Journal of the Marine Biological Association of the United Kingdom, 91: 837-844.

Sampedro, M.P.; González-Gurriará, E.; Freire, J. and Muino, R. 1999. Morphometry and sexual maturity in the spider crab Maja squinado (Decapoda: Majidae) in Galicia, Spain. Journal of Crustacean Biology, 9: 578-592.

Sato, T.; Ashidate, M.; Jinbo, T. and Goshima, S. 2006. Variation of sperm allocation with male size and recovery rate of sperm numbers in spiny king crab Paralithodes brevipes. Marine Ecology Progress Series, 312: 189-199.

Shuster, S.M. 2008. The expression of crustacean mating strategies. p. 224-250. In: R. Oliveira; M. Taborsky and H. Brockmann (eds), Alternative reproductive tactics: an integrative approach, Cambridge, Cambridge University Press.

Servicio Nacional de Pesca y Acuicultura. 2015-2019. Anuario estadístico de Pesca artesanal. Ministerio de Economía,
Fomento y Reconstrucción, Chile. Chilean national fishery statistics. Available at http://www.sernapesca.cl/. Accessed on 15 March 2020.

Somerton, D.A. 1980. A computer technique for estimating the size of sexual maturity in crabs. Canadian Journal of Fisheries and Aquatic Sciences, 37: 1488-1494.

Stevens, B.G.; Donaldson, W.E.; Haaga, J.A. and Munk, J.E. 1993. Morphometry and maturity of paired tanner crabs, Chionoecetes bairdi, from shallow and deepwater environments. Canadian Journal of Fisheries and Aquatic Sciences, 50: 15041516.

Storch, D.; Fernández, M.; Navarrete, S.A. and Pörtner, H.O. 2011. Thermal tolerance of larval stages of the Chilean kelp crab Taliepus dentatus. Marine Ecology Progress Series, 429: 157-167.

Storch, D.; Santelices, P.; Barria, J.; Cabeza, K.; Pörtner, H.O. and Fernández, M. 2009. Thermal tolerance of crustacean larvae (zoea I) in two different populations of the kelp crab Taliepus dentatus (Milne-Edwards). Journal of Experimental Marine Biology and Ecology, 212: 1371-1376.

Van Son, T.C. and Thiel, M. 2006. Mating behaviour of male rock shrimp, Rhynchocinetes typus (Decapoda: Caridea): Effect of recent mating history and predation risk. Animal Behaviour, 71: 61-70.

Varisco, M. and Vinuesa, J. 2011. Reproductive biology of the spider crab Leucippa pentagona (Decapoda: Epialtidae), in Bustamante Bay, Argentina. Latin American Journal of Aquatic Research, 39: 471-480.

Wedell, N.; Gage, M.J.G. and Parker, G.A. 2002. Sperm competition, male prudence and sperm-limited females. Trends in Ecology and Evolution, 17: 313-320. 